\title{
Reconstruction of Rector's Palace atrium in Dubrovnik: a key role of column connections
}

\author{
D. Lazarević, J. Atalić \& K. Fresl \\ Faculty of Civil Engineering, University of Zagreb, Croatia
}

\begin{abstract}
Rector's Palace is one of the most valuable heritage buildings in the historic Old town of Dubrovnik and the world famous setting for concerts and exhibitions. The Palace Atrium is surrounded by a two-storey structure comprising quadripartite masonry vaults supported by masonry walls and stone columns. Historically, this structure has suffered numerous collapses and damages and restorations were frequently made. Despite this, many distinct fractures are concentrated around the traditionally made column connections with capitals and bases. Carefully smoothed stone contact areas are joined with iron dowel, which is centrally placed in a slightly larger hole, with a lead infill. These contacts do not have sufficient rotational stiffness and the ability to transmit eccentric loads. Therefore, high edge stresses and fractures at connections are unavoidable. With time, the small rotational stiffness of joints becomes even smaller and the behaviour is approaching that of the hinge joint. This effect may endanger the global stability of this structure, as only three aligned hinges are sufficient to render the system unstable, i.e. the system is "almost" statically determinate and has only a small reserve in bearing capacity. Various retrofit strategies for column connections can cause considerably different stress distribution and by ignoring or underrating these effects, the safety factor can be seriously overestimated. This paper confirms the above assertions using a range of computational models: from simple frame and shell models to complex 3D solid models. This work also points out the significance of connections in historical buildings and attempts to investigate possible retrofit concepts. Numerous retrofit solutions were considered and results show a significant influence of this small detail of the bearing system on the global behaviour and stability of structure.
\end{abstract}

Keywords: historic stone masonry, column connections, dowel, contact stress. 


\section{Introduction}

The Rector's Palace is one of the most outstanding monuments of Gothic and Renaissance architecture, not only in Dubrovnik, but on the entire Adriatic coast. It is placed on the list of protected cultural monuments, established by the UNESCO organization. Written history of the Palace dates from the $13^{\text {th }}$ century and it is fairly well known that the present-day appearance is a result of numerous events that occurred throughout several centuries (Horvat-Levaj and Seferović [1]). Today, the Palace is a tourist and cultural centre, the location for various exhibitions and a world famous place for chamber music concerts. However, numerous fractures, damaged columns, stirrups, insets and broken parts seriously decrease the global impression of this monument. To illustrate the constancy of the problem, two characteristic quotations, found in the archives (Steinman [2]), could be mentioned: "... during the summer festival 1968 part of the capital fell down ..." and "... this is part of the capital from the left column near the clock, which was replaced in 1952." Some historical data and numerous vestiges of previous reconstructions show that we are dealing with a serious problem. In this paper, fundamental causes of permanent damages of column elements in the Atrium of the Rector's Palace are considered.

\subsection{Description of the atrium}

Rector's palace (fig. 1(a)) is a traditional structure placed inside the historical part of Dubrovnik, called the Old town. The massive stone walls of the Palace surround the inner opened structure, known as the atrium (fig. 1(b)), where the origins of the problem are located. It consists of two storeys, each defined by the quadripartite masonry vaults (fig. 1(c)), and filled with a weak material up to the floor level. The back side of the vaults is supported by masonry walls, while the front side lies on the stone columns, which mostly constitute the inner façade (fig. 2(a)). The first floor columns are coupled and have a smaller diameter, $d=23-25 \mathrm{~cm}$, than those on the ground floor, $d=50 \mathrm{~cm}$. Between columns, which carry the floor vaults, there are also columns that carry only decorative front arches. On the northern front, instead of on the row of columns, ground floor vaults lie on a long masonry wall, along which the stone stairway leads to the floor level (fig. 2(b)). At the corners, the floor vaults are supported by massive brick columns (marked on fig. 2(c)).
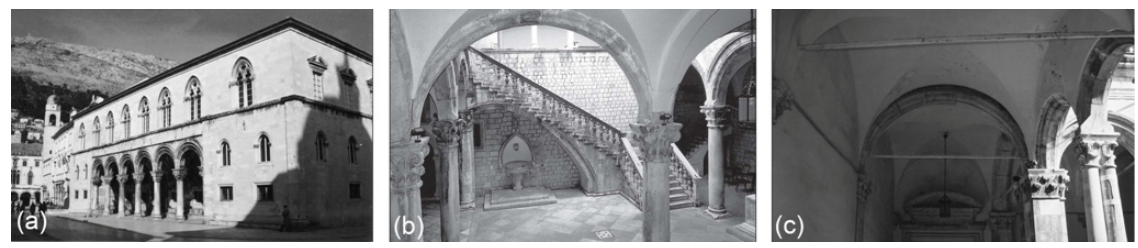

Figure 1: Rector's Palace: (a) front view, (b) atrium (ground floor), (c) atrium (first floor). 

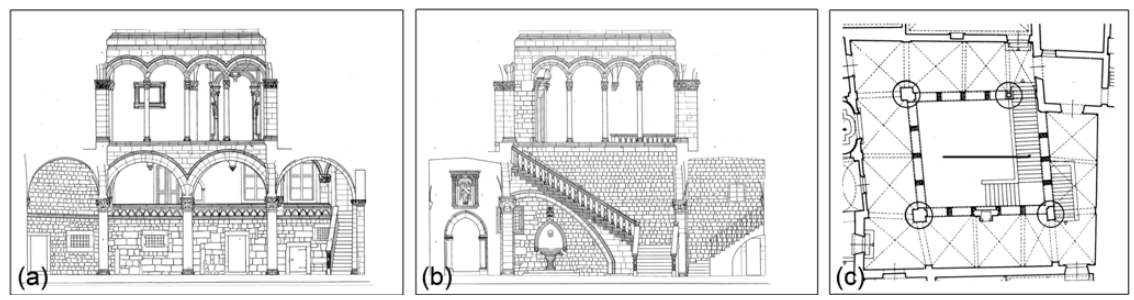

Figure 2: Atrium: (a) south front, (b) north front, (c) plan of the floor.


Figure 3: $\quad$ Fractures on column connections: (a) and (b) with capital, (c) with base.

Two additional bearing elements should be mentioned: braces below the floor arches and the reinforced concrete grillage placed in the infill of the terrace floor, both parts of previous reconstructions.

\subsection{Current condition of structural system}

Centuries will cause a deterioration in every structure. From historical reports and discussions with colleagues from various fields, who have worked on the Rector's Palace during the past four decades, it became apparent that the structure has suffered numerous damages throughout history. Intrigued by the characteristic fractures on the bases and capitals of many columns (fig. 3), a working hypothesis was made that the reasons of past collapses partly lie with the weak joints between the column elements. Indeed, many restorations were noted by chronicles and today numerous signs of these actions can be observed: different types of stones, various styles of column shapes and capitals, stirrups around columns, stone insets and gaps filled with led or wood. Wrong assertions about large compressive force in columns as the main reason of their collapse compelled old masters to remove heavy stone fence from the terrace. Almost forty years ago, structural engineer V. Steinman wrote in his report [2]: "Damages of particular parts of columns seem to represent a continuous phenomenon which required unusually large number of interventions". 
Today, it is obvious that the braces are not correctly placed, activated and anchored, few capitals are eccentrically loaded, and the beneficial action of any axial load due to weight of the fence is reduced. If the event of a gunpowder explosion in 1463, serious earthquakes in 1520, 1667, and 1979, many reconstructions (major in 1981), and presumably lots of unknown interventions are added, it is obvious that the underlying bearing system is seriously disrupted.

\section{Problem statement and hypothesis about structural behaviour}

The logical hypothesis about large relative vertical displacements between the columns, as the main reason of damages, was not confirmed by observations, geotechnical and surveying measurements. However, this statement is only conditionally discarded because of the short measurement time scale and the possibly slow (fig. 4(a)) or discontinuous (fig. 4(b)) ground displacements, where the latter appeared immediately after seismic event. These scenarios offer an explanation why precise instruments did not detect any movement over the period of a year or two.

Another hypothesis about the large uniform compressive stress in columns was also discarded, based on both experimental as well as numerical findings. Therefore, the solution to the problem was pursued further. Although there are "standard" reasons for deterioration in historical constructions which can always be used as the "reasons of damages" (dowels corrosion, for example), preliminary results pointed to a specific problem of column connections.

(a)

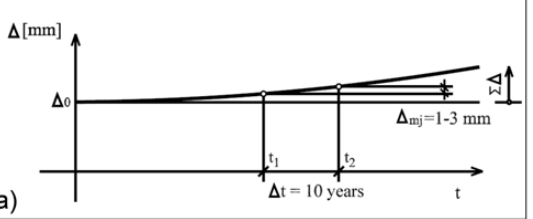



(b)

(a) slow and continuous, (b) immediate and discontinuous.

\subsection{Connection properties}

Detailed analysis of specific fractures around the column connections revealed some bad features of contact between the column and the base as well as the column and the capital. Carefully smoothed stone contact areas are joined with iron dowel which is centrically placed in a slightly larger hole and finally filled with lead (fig. 5(a)). Old masters must have thought that columns were uniformly compressed, so such precise finishing of contact areas was very well suited for transmission of such uniform vertical stresses. 


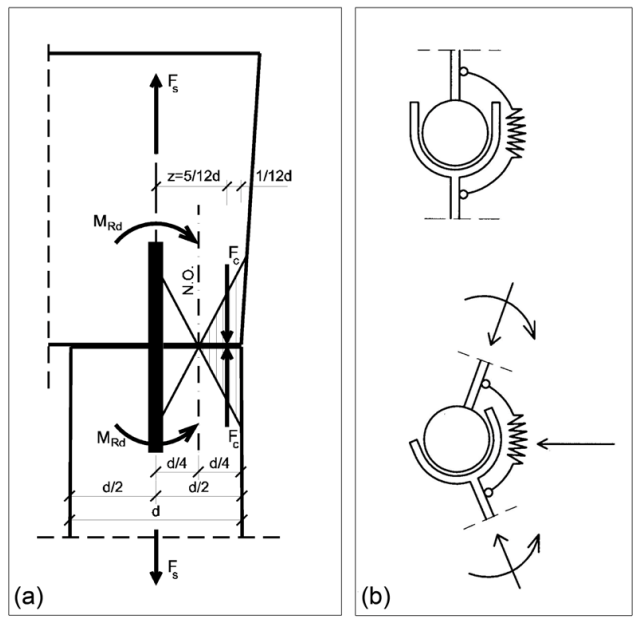

Figure 5: Connection Contact Model: (a) rotational capacity; (b) undeformed and deformed state.

Unfortunately, it will be shown in the next section that they were completely wrong. Furthermore, as the dowel can transmit only very small tensile force due to insufficient dowel anchoring (about $10 \mathrm{~cm}$ ) and the lack of adhesiveness amplified by the influence of weak mechanical properties of lead, especially its tendency to creep. Therefore, the dowel can safely maintain only compression and transverse force (with a help of friction between stones at contact). It is obvious that such a connection has a very small rotational stiffness and therefore the contact behaves almost like a hinge (more precisely, like a hinge with an added rotational spring with small stiffness). So, contact behaviour can be primarily described like a ball-in-a-cup (fig. 5(b)). Note, even intuitively, that such a contact is very sensitive to any horizontal disturbance.

\subsection{Eccentrically loaded joints}

Unfortunately, connections are mostly loaded eccentrically (note the position of the thrust line in fig. 8(b)). Even small horizontal displacement of connection causes relative rotation between column elements and results in high local stresses at the edge of a column, because the joint has only very limited ability to compensate rotations (fig. 6). When stress concentration exceeds the compression strength of stone, the deviation of compression trajectories generates unwanted tensile force which easily exceeds small tensile strength limit of stone and causes a column to split (fig. 7(a)). This force is effectively covered with stirrups (in reinforced concrete) or with steel rings (as it appears here), tightened around almost crumbled columns. Eventually, this leads to fractures near contact surfaces, splitting of columns and capitals and thereby a complete loss or a very significantly reduced bending stiffness. 



Figure 6: $\quad$ Progress of contact stresses with an increase of lateral load.
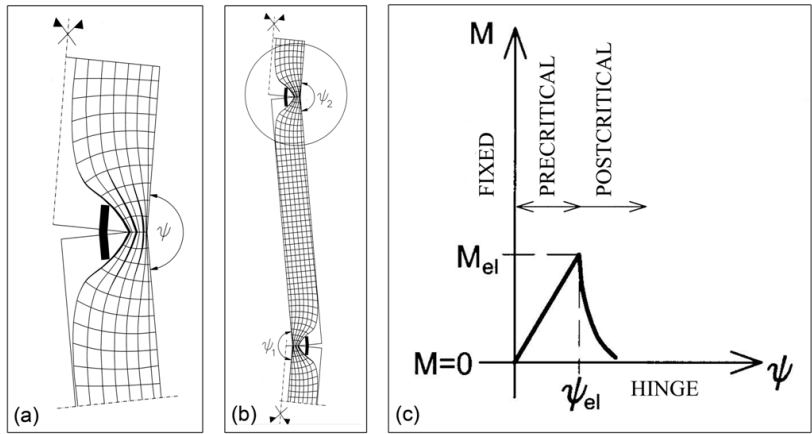

Figure 7: Contact behaviour: (a) position of cracks, (b) stress trajectories in column (c) approximate $\mathrm{M}-\psi$ diagram of contact.

The connection is still capable of transmitting compressive and shear forces and therefore can be idealised as a pure hinge. It should be noted that this problem is very localised as outside a range of approximately $3 d$ from the joint, the trajectories become parallel again (fig. 7(b)). Consequently, the body of the column experiences only moderate uniform compression stress and a large safety factor is maintained.

\subsection{Lack of redudancy}

However, if the connections are idealised as hinges (fig. 8(a)), the eccentrically loaded bearing system (fig. 8(b)) can easily turn into a mechanism. Note that only three hinges on the characteristic vertical line are sufficient to render the system unstable (fig. 8(c)). Eventually, most of connections are seriously cracked (on the descending part of $\mathrm{M}-\psi$ curve; see fig. 7(c)) and the global bearing capacity of the atrium is almost exhausted (fig. 8(d)). Structure does not have bearing capacity reserves and the overstressed joints cannot effectively unload. High contact stresses cannot be redistributed to neighbouring bearing elements 


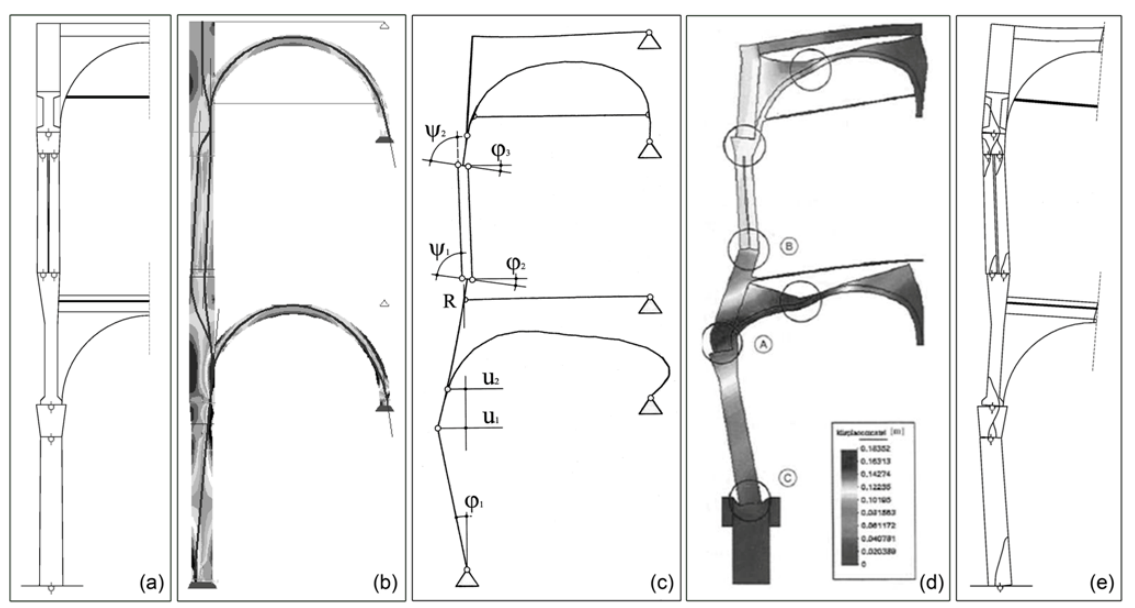

Figure 8: Behaviour of characteristic section: (a) position of hinges, (b) thrust line, (c) frame model, (d) stresses in section, (e) calculated cracks.

due to the small degree of indeterminacy. It is interesting to note that the computed crack positions (fig. 8(e)) is in agreement with those found on the real structure.

It can be concluded that the system equilibrium is maintained in the fractured state, stability of which depends on the weakest material property of the stone the small tensile strength which ensures only a weak fixity of joints. Without it, the structural system would have sufficient number of hinges to become a mechanism.

\subsection{Additional difficulties}

The state of equilibrium, which is maintained only by the rotational stiffness of cracked stone is very sensitive to any load changes. Even everyday temperature gradient causes both increase as well as decrease of the compression zone and the corresponding changes of splitting forces directly influence opening and closing of cracks. Therefore there is constant activity within these connections and the associated propagation of fractures (fig. 9). If a large vertical load were to exist, it would compress the joints and it would centre the thrust lines, thereby minimizing the problem of the local overstress. Unfortunately, the measured values show a low level of compressive stress in the columns. Axial forces in columns were additionally reduced by the removal of massive stone balustrade from the atrium terrace in 1952. The trouble is that such weakly compressed columns are also very slender, having small core sections and therefore are highly sensitive to any load eccentricity.

Additional stresses due to the pressure of corroded dowels are also present. It is well known that the corrosion causes an increase in the dowel volume and hence local pressure and splitting forces are significantly magnified. Braces 


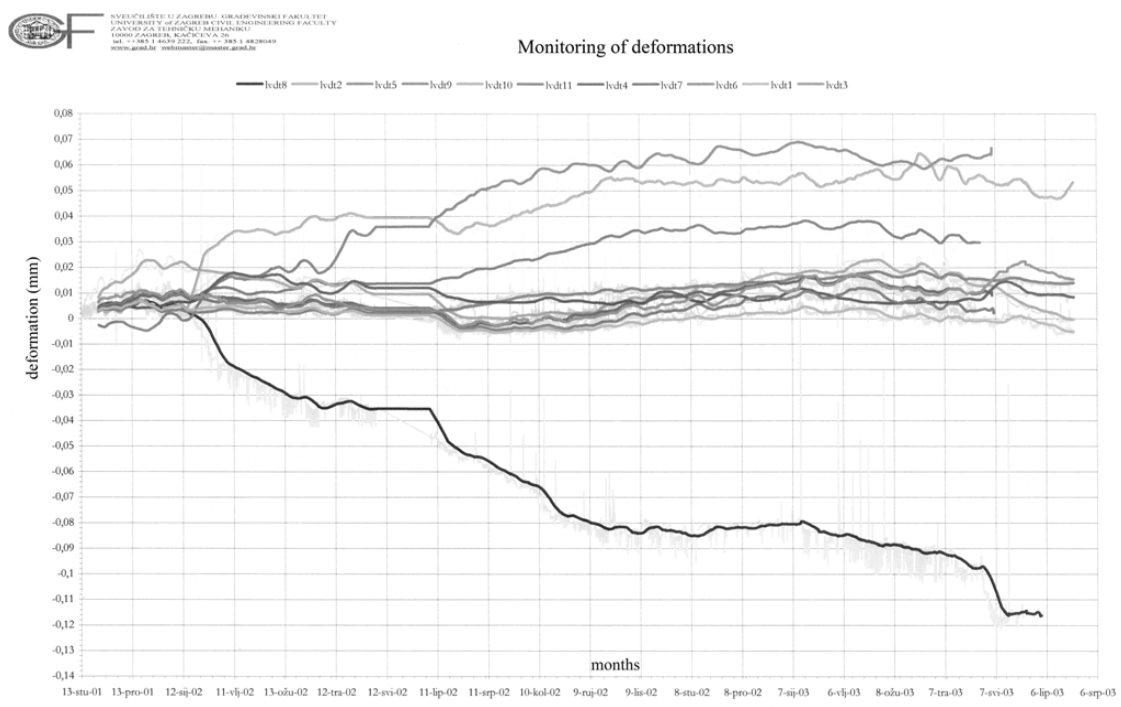

Figure 9: $\quad$ Monitoring of active cracks as measured during a period of 22 months.

which were added below the terrace vaults are much more efficient in preventing the horizontal displacements, rather than the rotation angles.

Their bending stiffness is negligible to prevent the rotation of the anchored place. It should be emphasized that these displacements and rotations are very small. Computational simulation indicates that the first crack opens with the horizontal displacement of the contact of less than one millimetre.

Further concern arises from the fact that Dubrovnik is placed in a region of high seismicity, with an expected peak ground acceleration of around $0.4 \mathrm{~g}$. In 1981 Rector's Palace was reinforced to sustain moderate earthquake loads, but since then new regulations require consideration of significantly increased loads. Massive walls around atrium should be able to sustain most earthquake forces but will also displace horizontally. As the walls are connected with vaults, these displacements will be common and will affect the atrium. Therefore, rotations of the column elements will invariably additionally increase.

It should be mentioned that the role of fracture mechanics is significant here. Even an earthquake of lower intensity produces enough energy to exceed the small fracture energy of a brittle material like stone. Energy needed for fracture propagation is proportional to the volume of the damaged area. So, fractures can easily propagate through slender and fragile elements like the tiny columns in the atrium.

\section{Numerical modelling strategies}

Various computational models have been constructed to support the above statements and to test the effects of rotational stiffness on the stress distribution and particularly on the local and global stability of the structure. 

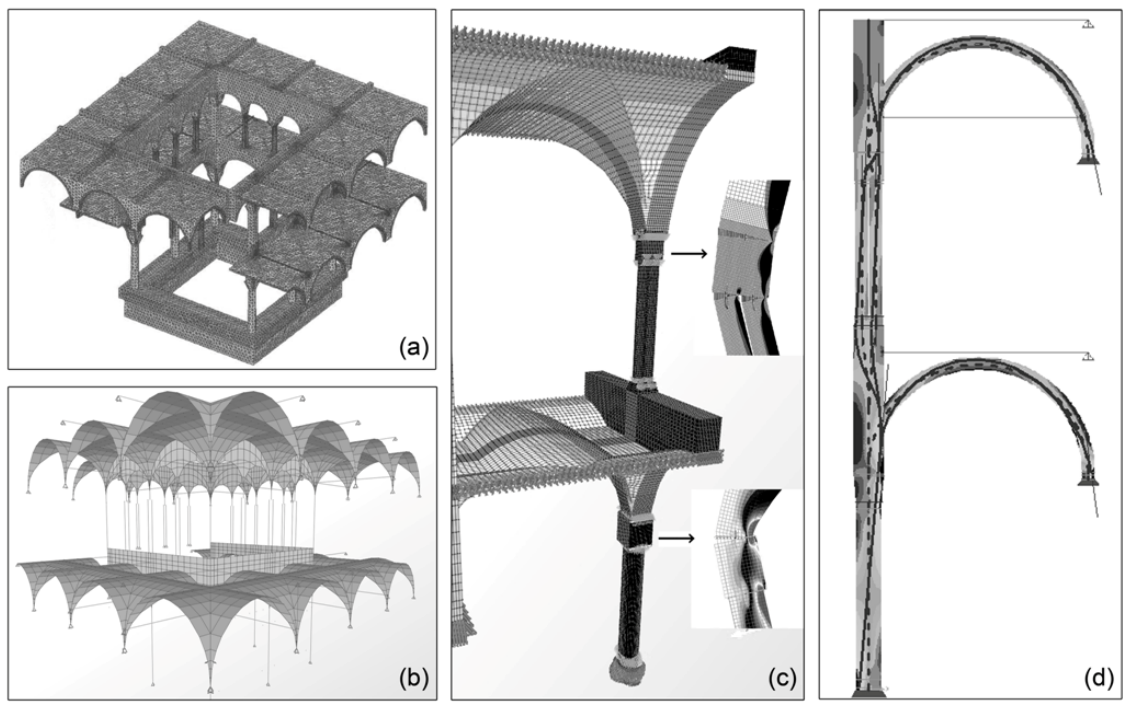

Figure 10: Computational models: (a) with brick elements, (b) with frame and shell elements, (c) contact stresses, (d) lines of thrust.

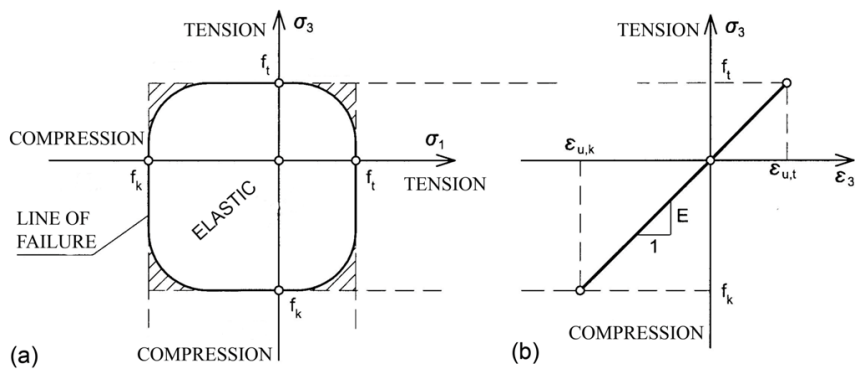

Figure 11: Fracture criterion: (a) failure surface, (b) one dimensional $\sigma-\varepsilon$ curve.

\subsection{Model of complete structure}

Computational model of the complete structure, with tetrahedral finite elements, was analysed using FEAP 7.4 (Taylor [3]) combined with GiD 6.1.2a [4] for pre and post processing purposes (fig. 10(a)). Several novel subroutines were implemented into the basic linear elastic FEAP model, to better describe the connection behaviour. Program code was extended to exclude overstressed finite elements and to search the minimal energy in given direction (line search) using the bisection method to improve the convergence of the incremental Newton Raphson technique. For the purpose of numerical integration on tetrahedron (with ten nodes and three degrees of freedom per node), four Gauss points were used. 
Failure criterion of material was defined by the modified theory of normal stresses, which was originally developed by Galileo and Rankine. This simple theory predicts the failure of an initially elastic material, with no ductility and no post critical reserves. Fracture criterion is defined by the expression:

$$
f\left(\sigma_{1}, \sigma_{3}\right)=\frac{\left(\sigma_{1}-\sigma_{a}\right)^{n}}{\sigma_{s}}+\frac{\left(\sigma_{3}-\sigma_{a}\right)^{n}}{\sigma_{s}} .
$$

where $\sigma_{1}$ and $\sigma_{3}$ are the highest and the smallest principal stress at the Gauss point of an element. Here, positive values imply tensile, and the negative value implies compressive stress (fig. 11). The values $\sigma_{\mathrm{a}}$ and $\sigma_{\mathrm{s}}$ are defined by:

$$
\sigma_{a}=\frac{f_{t}-f_{k}}{2}, \quad \sigma_{s}=\frac{f_{t}+f_{k}}{2} .
$$

Based on this criterion, materially nonlinear analysis with load increments of $1 \%$ of the total load was conducted. Within each step, the full Newton - Raphson method was applied. Stability of the analysis was monitored by the line search method, using the bisection for computing a zero point and an underrelaxation factor equal to 0.8 was adopted for additional stability purposes. Convergence criterion was based on an energy norm. Convergence was deemed to have been achieved and the next step was started if the current energy was lower than $10^{-5}$ of the energy at the start of the step. Using this algorithm, stress concentrations and the exclusion of overstressed elements were easily detected. Degradation of stiffness was monitored by plotting the relation between the first eigenvalue of tangent global stiffness matrix and the safety factor for estimated dead load (fig. 12). After three substantial step changes in the eigenvalues, here labelled as A, B and $\mathrm{C}$ (three hinges were developed), the global stiffness was so small that the model became practically unstable.

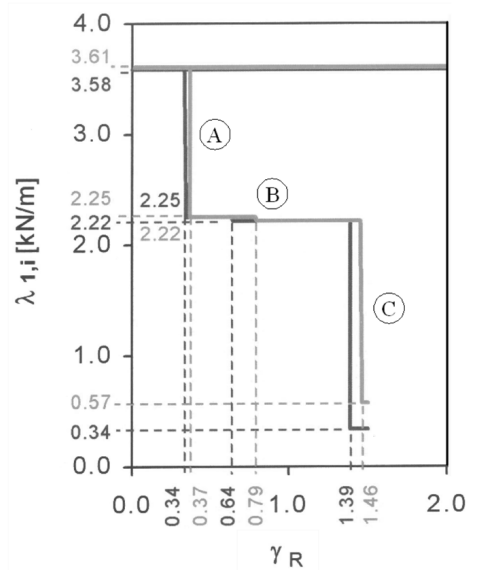

Figure 12: Decrease of the first eigenvalue of the global tangent stiffness matrix. 


\subsection{Detailed model of the characteristic cross section}

Detailed model of the column connections was preformed with SAP2000 [5] using brick elements with incompatible modes and 'links' (gaps) elements, which are able to exclude tension stresses (fig. 10(c)). Minor fractures in the vault bearing system were ignored and links were used only at column connections including properties of lead and the dowel. Even this simple approach was sufficient to obtain contact rotations and overstressing at the edges. Behaviour and positions of overstressed elements matched fairly well with observed fractures.

Further computational models of various complexities were explored to assess suitability of simplified models for general usage. For example, the same gap elements were used for the contact behaviour on a simple planar model of the characteristic section (fig. 10(d)). In this model, the gap opening and its influence on the stress distribution and the lines of thrust (continuous and dashed lines) are easily followed. Also, the effect of contact properties on the shape of the thrust line can be seen, if the position of centred (dashed) and inclined (continuous) line are compared. It is easy to see that the dashed thrust streamlines are in agreement with high compressive stresses. Completely different behaviour can be expected if the line of thrust is centrally placed. In such a case, the best of the stone properties - its great compressive strength - is beneficial.

Regardless of the level of sophistication of the chosen computational setting, the line of thrust should still be used as a fundamental technique for preliminary analysis of historical constructions. This simple and approximate approach always shows main structural weaknesses that cannot be ignored.

\subsection{Simplified model}

Mixed frame and shell model of a complete structure (fig. 10(b)) was finally made to study the influence of different rotational stiffnesses obtained from detailed models. The columns were modelled with frame elements and rotational stiffness between them was included in the form of a rotational spring. The effects of previously known or recorded reconstructions were included approximately by the staged construction technique to correctly activate subsequently inserted elements. All analyses accounted for geometrical nonlinearity through the P-delta effect. As the level of the rotational stiffness changed, the model behaviour and the results were influenced significantly. The global model is highly sensitive to the changes on local contact properties. This approach provided insight into the stability problem and the evaluation of the safety factor. Another important benefit was the evaluation of maximal angles of rotations at joints, which identified the size of required dilatation needed for the connections repair.

Various models confirmed the importance and the need for the proper assessment of the column connections. The level of rotational stiffness was crucial for the understanding of load carrying mechanism and for finding a correct distribution of stresses and assessment of the global stability of structure. 
It is hard to present unique rule for the analysis of column contacts because there are various types of columns, joints and structural systems. However, the importance of details can be emphasized by the fact that safety factor for this structure dropped from 10 for standard continuous elastic model to 1.4 for models based on assumptions presented.

\section{Possible retrofit strategies}

Analyses results confirmed our assertions about problematic column connections and the need to act in order to preserve both the local and global stability of the structure. Previous history of Rector's palace is ripe with inadequate interventions and one of the goals must be to extend the time without new fractures of columns as much as possible.

Some form of repair (or even replacement) of critically damaged columns and capitals is clearly inevitable. Proposed intervention will include thin layer of lead $(4 \mathrm{~mm})$ placed between the two connected areas (fig. 13(a)). The material such as lead will enable small rotations and will shield connected areas from large stress concentrations. Lead is already used to fill dowel holes and the additional horizontal thin layer appears as an appropriate and almost invisible intervention.

In order to reduce load eccentricity in columns, which primarily exists due to thrust of first floor vaults, new braces are envisaged. These will be slightly prestressed $(30 \mathrm{kN})$ and properly anchored. This visible (and frequently unpopular) intervention is needed if the thrust line is to be centred, which will in turn minimize consequences of serious earthquakes. Furthermore, existing braces and anchors from earlier interventions at the second floor are overstressed and must be replaced in any case. This issue is absolutely vital, as without them, the thrust line lies outside the column section and the structure is unable to sustain even a dead load.

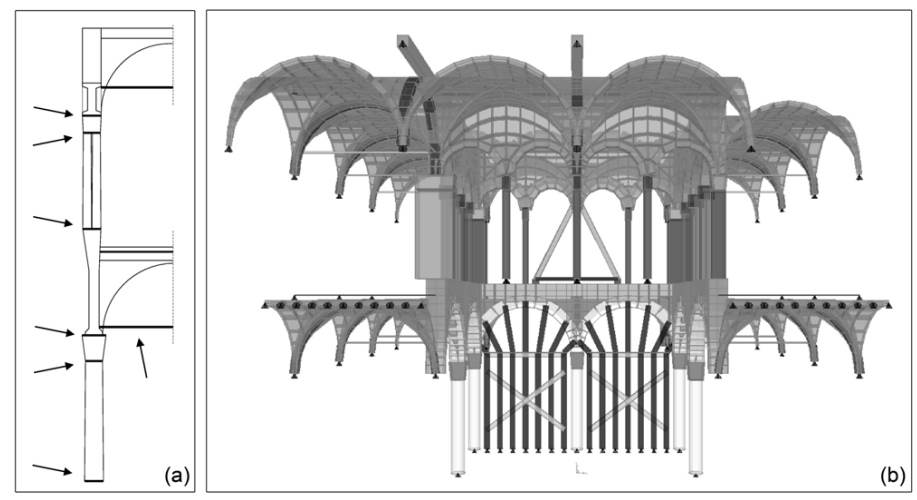

Figure 13: Reconstruction: (a) locations of intervention, (b) numerical model. 
All potential reconstruction phases were also checked using a nonlinear staged construction model, with element inclusion/exclusion when required as the analysis progresses in time. These elements were carefully placed in such a way that loads on structural elements in all intervention phases were on the conservative side (fig. 13(b)). With these interventions, the safety factor of the structure is increased by approximately $20 \%$ and it is hoped that any future interventions on columns will be significantly delayed.

A continuous, long term monitoring is imperative because presented analyses are based on a number of unknown and/or assumed data. As - for obvious reasons - destructive testing methods are not appropriate for historic buildings, insufficient data usually exists to characterise constitutive model parameters. Therefore, non-destructive experimental strategies must also be considered and/or further refined.

\section{Conclusion}

The importance of correct analysis of stone column connections is emphasized, along with the complexities and difficulties associated with such process. Slender columns are usually identified as the weakest link in historical constructions. If the hypotheses about the uniform stress distribution cannot be proven for a specific situation, it is vital to fully appreciate the behaviour of the adopted contact details. It was shown that, for the analysed structure of Rector's Palace Atrium in Dubrovnik, that the joints lack sufficient rotational stiffness and the eccentricity effects due to dead load (inclined thrust lines) cause fractures at places of contact. It is concluded that ignoring or not fully appreciating the real nature of connections leads to significantly different stress distributions and orientations of thrust lines which may grossly overestimate the safety factor. Moreover, the propagation of fractures near the column connections can easily endanger the global stability of structure.

\section{References}

[1] Horvat-Levaj, K. \& Seferović, R., Baroque Restoration of the Rector's Palace in Dubrovnik, Radovi Instituta za povijest umjetnosti, 27, pp. 163168, 2003.

[2] Steinman, V., Research work on Rector's Palace in Dubrovnik with basic recommendations for reconstruction, (in Croatian) Book II, Civil Engineering Institute of Croatia: Zagreb, pp. 50-83, 1974.

[3] Taylor, R.L., FEAP - A Finite Element Analysis Program, Version 7.3, Programmer Manual, Department of Civil and Environmental Engineering, University of California: Berkley, pp. 20-48, 2001.

[4] GiD, The universal, adaptive and user friendly pre and post processing system for computer analysis in science and engineering, Reference Manual Version 6, CIMNE: Barcelona, pp. 127-141, 2000.

[5] SAP2000, Integrated Software for Structural Analysis and Design, Analysis reference manual, CSI: Berkeley, pp. 189-224, 2002. 
[6] Lazarević, D., Dvornik, J. \& Fresl, K., Analysis of damages to the Rector's Palace atrium in Dubrovnik, Građevinar, 56(10), pp. 601-612, 2004.

[7] Lazarević, D., Dvornik, J., Fresl, K. \& Rak, M., Numerical analysis of damages of the Rectors's Palace atrium in Dubrovnik. Proc. of the Int. Conference Heritage Protection - Construction Aspects, eds. J. Radić, V. Rajčić \& R. Žarnić, SECON HDGK: Dubrovnik, pp. 109-116, 2006.

[8] Atalić, J., Lazarević, D. \& Fresl, K., Influence of Rotational Stiffness between Column Elements on Global Stability of Historical Constructions. Proc. of the $8^{\text {th }}$ European Conference on Research for Protection, Conservation and Enhancement of Cultural Heritage: book of abstract, eds. J. Kolar, \& M. Strlić, Narodna in univerzitetna knjižnica: Ljubljana, pp. 6062, 2008.

[9] Palmisano, F., Vitone, A., \& Vitone, C., Load path method in the interpretation of masonry vault behaviour. Structural Studies, Repairs and Maintenance of Heritage Architecture IX, eds. C.A. Brebbia \& A. Torpiano, WIT Press: Southampton, pp. 155-168, 2005.

[10] Meli, R. \& Sanchez-Ramirez, A.R., Structural aspects of the rehabilitation of the Mexico City Cathedral. Int. Sem. Structural Analysis of Historical Constructions. Possibilities of numerical and experimental techniques, eds. P. Roca, J.L. Gonzales, A.R. Mari \& E. Onate, CIMNE: Barcelona, pp. 123-140, 1997.

[11] Theodossopoulos, D., Structural design of high gothic vaulting systems in England, International Journal of Architectural Heritage, 2(1), pp. 1-24 2008.

[12] Macchi, G., Problems related to the original conception - The case of Pavia Cathedral. Int. Sem. Structural analysis of historical constructions II. Possibilities of numerical and experimental techniques, eds. P. Roca, J.L. Gonzales, E. Ońate \& P. Lourenço, CIMNE: Barcelona, pp. 123-140, 1998.

[13] Binda, M.L., Saisi, A., Messina, S. \& Tringali, S., Mechanical damage due long term behaviour of multiple leaf pillars in Sicilian Churches. Proceedings of the $3^{\text {rd }}$ International Seminar Historical Constructions 2001. Possibilities of numerical and experimental techniques, eds. P. Roca \& P. Lourenço, University of Minho: Guimaraes, pp. 707-718, 2001.

[14] Gubane, A, \& Giuriania, E., Structural restoration of vaults with extrados ties. Int. Sem. Structural Analysis of Historical Constructions IV. Possibilities of numerical and experimental techniques, eds. C. Modena, P. Roca \& P.B. Lourenço, A. A. Balkema: London, pp. 745-752, 2004. 